\title{
PENGARUH PERSEPSI HARGA, PROMOSI DAN KUALITAS LAYANAN TERHADAP KEPUTUSAN PEMBELIAN (STUDI PADA PERUSAHAAN RITEL DI JAKARTA)
}

\author{
Steven Ferdyanto \\ Program Studi Magister Manajemen Universitas Tarumanagara \\ stevenlimanajaya93@gmail.com
}

Masuk : 07-06-2020, revisi : 26-06-2020 diterima untuk diterbitkan : 29-06-2020

\begin{abstract}
The purpose of this research is to get empirical evidence about the influences of perceived price, promotion, and service quality on purchase decision. The method used was multiple regression method with SPSS version 22 program. Sample size was 200 people at the one of Hypermarket as respondents. Data was collected by using non probability sampling method. The instrument used in the form of a structured questionnaire of 35 questions arranged based on indicator and dimensions derived from each variable. The result showed that perceived price, promotion, and service quality had positive and significant influence to purchase decision.
\end{abstract}

\begin{abstract}
Abstrak: Tujuan dari penelitian ini adalah untuk mendapatkan bukti empiris tentang pengaruh persepsi harga, promosi, dan kualitas layanan terhadap keputusan pembelian pada perusahaan ritel di Jakarta. Penelitian ini menggunakan metode regresi berganda dengan program SPSS versi 22. Ukuran sampel adalah 200 orang pada salah satu Hypermarket sebagai responden. Data dikumpulkan dengan menggunakan metode non probability sampling. Instrumen yang digunakan berupa kuesioner terstruktur terdiri dari 35 pertanyaan yang disusun berdasarkan indikator dan dimensi yang berasal dari masing-masing variabel. Hasil penelitian ini bahwa persepsi harga, promosi, dan kualitas layanan berpengaruh positif dan signifikan terhadap keputusan pembelian.
\end{abstract}

Keywords: Perceived Price, Promotion, Service Quality, Purchase Decision

\section{PENDAHULUAN}

Persaingan keputusan pembelian yang dihadapi oleh Hypermarket merupakan unsur penentuan kemajuan dalam suatu retail. Kotler dan Keller (2016) mengungkapkan bahwa proses pembelian keputusan terdiri atas problem recognition, information search, evaluation of alternatives, purchase decision. Pengambilan keputusan menjadi sesuatu hal yang sangat penting untuk di perhatikan karena hal tersebut merupakan sebuah proses dalam pembelian nyata setelah mencari informasi, melakukan identifikasi masalah, evaluasi alternatif, dengan demikian konsumen dapat memutuskan apakah akan melakukan pembelian atau tidak.

Pemasaran merupakan suatu hal yang sangat penting dan merupakan elemen yang vital untuk kesuksesan sebuah bisnis, hal ini disebabkan dengan terus bertambahnya konsumsi masyarakat terhadap suatu barang dan jasa, maka keuntungan perusahaan dapat meningkat. Saat ini persaingan dalam dunia perdagangan juga terbilang sangat ketat. Perdagangan bebas yang begitu keras membuat dunia seolah tanpa batas disebabkan adanya peran globalisasi. Dalam perdagangan internasional banyak produsen barang dan jasa dari sebuah negara yang bersaing dengan negara lain untuk menarik minat konsumen. Di Indonesia saat ini jaringan peritel modern juga terus tumbuh karena di pandang terus mengikuti karakter konsumen di Indonesia yang menjadikan belanja sebagai sebuah bagian dari hiburan.

Persaingan keputusan pembelian yang dihadapi merupakan unsur penentuan kemajuan dalam suatu Hypermarket. Kotler dan Keller (2016) mengungkapkan bahwa proses pembelian 
keputusan terdiri atas problem recognition, information search, evaluation of alternatives, purchase decision. Pengambilan keputusan menjadi sesuatu hal yang sangat penting untuk di perhatikan karena hal tersebut merupakan sebuah proses dalam pembelian nyata setelah mencari informasi, melakukan identifikasi masalah, evaluasi alternatif, dengan demikian konsumen dapat memutuskan apakah akan melakukan pembelian atau tidak.

Dalam menentukan keputusan pembelian faktor persepsi harga merupakan salah satu faktor yang dianggap paling menarik. Faktor promosi juga sangat penting untuk dilaksanakan oleh suatu perusahaan dalam memasarkan sebuah produk. Brata et al (2017) mengatakan bahwa setiap kegiatan promosi perusahaan tentang cara mengenalkan, menginformasikan atau mempromosikan produk mereka, sehingga konsumen akan memilih jenis barang dan jasa, karena betapapun bagusnya kualitas produk, harga mungkin terjangkau bagi konsumen, dan pengiriman produk yang tepat waktu kepada konsumen, semua ini bukan jaminan kesuksesan produk di pasar, maka promosi merupakan faktor penting yang harus diwujudkan. Selain itu faktor penentu yang dapat mempengaruhi keputusan pembelian ialah service quality.

Tujuan penelitian ini adalah Untuk mendapatkan bukti empiris mengenai pengaruh persespsi harga, Promosi dan Kualitas Layanan terhadap keputusan pembelian. Hasil penelitian ini diharapkan dapat memberikan saran Hypermarket dalam penelitian ini guna meningkatkan penjualan produk melalui program-program selanjutnya.

\section{TELAAH KEPUSTAKAAN Persepsi Harga}

Zeithaml (1988:10) menyatakan "Perceived price is defined as what a consumer gives up or sacrifices in order to obtain a product." Definisi di atas menjelaskan bahwa persepi harga merupakan sesuatu yang diserahkan atau dikorbankan oleh konsumen untuk mendapatkan suatu produk. Sementara Beneke dan Zimmerman (2014:303) menyatakan bahwa "Perceived price should reflect the value that the consumer obtains from purchasing a good". Definisi ini mengatakan bahwa harga yang dirasakan harus mencerminkan nilai yang diperoleh konsumen dari membeli barang. Selanjutnya Malik dan Yaqoob (2012:487) menyatakan persepi harga adalah "the process by which consumers interpret price and attribute value to a good or service proceess", yang berarti sebuah proses dimana pelanggan menafsirkan nilai harga dan atribut ke barang atau layanan yang diinginkan.

\section{Promosi}

Boone dan Kurtz (2002:129) "promotion is the process of informing, persuading, and influencing a purchasing decision" yang artinya promosi merupakan sebuah proses menginformasikan, membujuk dan mempengaruhi suatu keputusan pembelian. Menurut Brata (2017:435) menyatakan bahwa "Promotion can be defined as a form marketing communication, marketing communication is activity that seeks to disseminate information, influence / persuade and/or alerting the target market for the company and its products offered by the company concerned." Promosi dapat didefinisikan sebagai bentuk komunikasi pemasaran, komunikasi pemasaran adalah kegiatan yang berupaya menyebarluaskan informasi, mempengaruhi / membujuk dan / atau mengingatkan target pasar untuk perusahaan dan produk-produknya yang ditawarkan oleh perusahaan yang bersangkutan. Selanjutnya Andreti et al. (2013:74) "promotion is communication by marketers that informs, persuades, and reminds potential buyers of a product in order to influence their opinion."

\section{Kualitas Layanan}

Menurut Palmer (2011:287) kualitas layanan ialah "is highly abstract construct in contrast to goods where technical aspect of quality predominate." Kualitas layanan merupakan konstruksi yang sangat abstrak berbeda dengan barang-barang yang didominasi oleh aspek teknis kualitas. Selanjutnya menurut Parasuraman, Zeithaml dan Berry (1985: 42) menyatakan "Service quality is the result of a comparison between what customers consider the service should be and their perceptions about the performance offered by the service provider." Teori 
ini merupakan hasil perbandingan antara apa yang pelanggan anggap sebagai layanan dan persepsi mereka tentang kinerja yang ditawarkan oleh penyedia layanan. Sementara menurut Lahindah (2017:120) kualitas layanan adalah "a capital that gets describes the condition of the customer by comparing the service they expect with what they receive in evaluating the quality."

\section{Kaitan antara Persepsi Harga dengan Keputusan Pembelian}

Penelitian yang dilakukan Oscar dan Keni (2019) menjelaskan bahwa dengan mempertahankan standar harga maka akan meningkatkan partisipasi pengunjung, kesadaran dan keputusan pembelian konsumen. Sejalan dengan penelitian tersebut penelitan Brata, et al. (2017) dalam penelitiannya, menjelaskan bahwa semakin banyak diskon harga yang diberikan oleh perusahaan akan meningkatkan keputusan pembelian konsumen, sehingga hal ini yang harus diperhatikan oleh sebuah perusahaan. Andreti, et al. (2013) dalam penelitiannya, menjelaskan bahwa, sebagian pelanggan datang ke toko karena harga yang ditawarkan oleh tersebut, hal ini menjadi bukti bahwa pandangan konsumen terhadap sebuah harga merupakan hal yang penting dalam keputusan pembelian. maka hipotesis penelitian adalah sebagai berikut.

H1 : Terdapat pengaruh positif persepsi harga dengan keputusan pembelian

\section{Kaitan antara Promosi dengan Keputusan Pembelian}

Brata et al (2017) mengatakan bahwa promosi adalah bagian dari pemasaran untuk menyebarluaskan informasi, membujuk, maupun mengingatkan target pasar agar mau memutuskan untuk membeli produk yang di promosikan. promosi yang lebih baik dan lebih menarik akan meningkatkan keputusan pembelian. Sejalan dengan pernyataan tersebut, Andreti et al (2013) dalam penelitian menyebutkan promosi memainkan peran penting dalam keputusan pembelian. Menciptakan promosi yang baik terhadap sebuah produk dapat memberikan efek yang cukup kuat ketika konsumen ingin membeli produk yang disukai dan tentunya dengan melakukan promosi yang lebih menarik dan memberikan lebih banyak diskon dapat meningkatkan kesadaran pelanggan dalam memutuskan pembelian. Hapzi et al (2018) juga menyatakan bahwa dengan melakukan promosi memanfaatkan semua media promosi yang ada, baik itu cetak, elektronik maupun digital serta media promosi outdoor yang dilakukan secara berkala tetapi terus menerus akan menarik minat konsumen dalam memutuskan pembelian. maka hipotesis penelitian adalah sebagai berikut.

$\mathrm{H} 2$ : Terdapat pengaruh positif promosi dengan keputusan pembelian

\section{Kaitan antara Kualitas Layanan dengan Keputusan Pembelian}

Penelitian yang dilakukan Firdausy dan Idawati (2017) menjelaskan bahwa, perusahaan perlu memberikan perhatian yang lebih besar kepada kualitas layanan, ketika perusahaan dapat meningkatkan kualitas layanan yang baik maka akan meningkatkan kesadaran konsumen untuk datang dan berbelanja. hal serupa juga disampaikan Andreti et al (2013) dalam penelitiannya, menyatakan bahwa pelanggan yang datang ke dikarenakan kualitas layanan yang diberikan. Oleh karena itu kualitas layanan yang baik dan kompetitif menjadi peran penting dalam keputusan pembelian konsumen. Selanjutnya penelitian yang di lakukan Lahindah et al (2018) menjelaskan bahwa kualitas layanan yang kompetitif pada layanan mereka kepada pelanggan membuat pelanggan semakin banyak datang ke untuk berbelanja. maka hipotesis penelitian adalah sebagai berikut.

H3 : Terdapat pengaruh positif kualitas layanan dengan keputusan pembelian

Berdasarkan uraian kaitan antara variabel-variabel penelitian di atas, maka model penelitian adalah sebagai berikut:

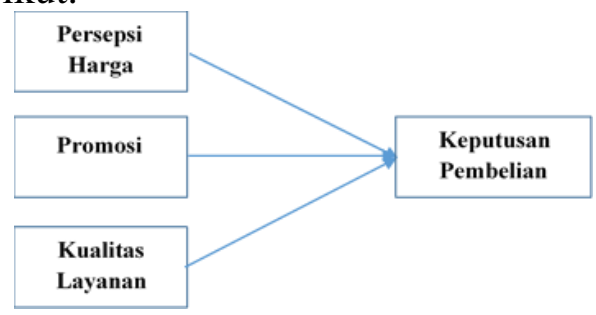




\section{METODE PENELITIAN}

Jenis penelitian yang digunakan dalam penelitian ini adalah jenis penelitian deskriptif. Periode penelitian ini dilakukan dari tahun 2019 sampai 2020. Sumber data penelitian ini adalah data primer, dimana data tersebut didapatkan langsung dari responden. Teknik pengumpulan data yang digunakan dalam penelitian ini adalah kuisoner online menggunakan google form kepada konsumen salah satu Hypermarket. Populasi dalam penelitian ini adalah konsumen yang berbelanja pada salah satu Hypermarket di Jakarta. Di mana mengingat banyaknya jumlah konsumen pada Hypermarket, maka tidak memungkinkan untuk melakukan penelitian berdasarkan populasi. Oleh karena itu peneliti melakukan penelitian dengan menggunakan sampel. Metode pengambilan sampel dalam penelitian ini adalah menggunakan metode non probability sampling. Teknik pemilihan sampel yang digunakan dalam penelitian ini adalah convenience sampling. Menurut Roscoe (1975) dalam Sekaran dan Bougie (2013) ukuran sampel lebih dari 30 dan kurang dari 500 merupakan ukuran yang sesuai untuk sebagian besar penelitian. Penelitian ini menggunakan sampel sebanyak 200 sampel.

Analisis regresi ganda digunakan untuk menguji apakah persepsi harga, promosi dan kualitas layanan memiliki pengaruh terhadap keputusan pembelian produk Hypermarket.

\section{HASIL DAN PEMBAHASAN}

Data kuisioner yang didapat mengenai jenis kelamin dari dua ratus orang responden sebagai berikut sebanyak 111 orang $(55,5 \%)$ berjenis kelamin perempuan. data mengenai usia dari dua ratus orang responden sebagai berikut: sebanyak 116 orang (58\%) berusia antara 2030 tahun. data mengenai pekerjaan dari dua ratus orang responden sebagai berikut: sebanyak 101 orang $(50,5 \%)$ memiliki pekerjaan sebagai karyawan, data mengenai pengeluaran per bulan dari dua ratus orang responden sebagai berikut: sebanyak 57 orang $(28,5 \%)$ memiliki pengeluaran per bulan sebesar Rp. 2.000.000,00 - Rp. 3.999.999,00. data mengenai seberapa sering berbelanja dari dua ratus orang responden sebagai berikut: sebanyak 110 orang (55\%) dalam sebulan 1-3 kali berbelanja. data mengenai alasan berbelanja dari dua ratus orang responden sebagai berikut: sebanyak 73 orang $(36,5 \%)$ memiliki alasan harga yang terjangkau. data mengenai barang yang dibeli dari dua ratus orang responden sebagai berikut: sebanyak 98 orang (49\%) membeli makanan dan minuman ringan. Hasil seluruh uji asumsi yang dilakukan telah terpenuhi yang terdiri dari uji normalitas, uji multikolinieritas dan uji heteroskedastisitas. Taraf signifikansi yang digunakan dalam penelitian ini adalah 5\%.

Hasil uji asumsi klasik menunjukkan bahwa uji regresi ganda dapat dilakukan untuk menganalisis data, karena tidak terdapat multikolinearitas, tidak terjadi heterokedastisitas, dan terdistribusi normal. Hasil analysis regresi ganda memiliki persamaan $\mathrm{KP}=2,537+0,211 \mathrm{PH}$ $+0,112$ PROM + 0,097 KP. Hal tersebut dapat disimpulkan bahwa variabel persepsi harga berperan paling besar di antara variabel lain.

Tabel 1

\begin{tabular}{|c|c|c|c|c|c|}
\hline \multirow[t]{2}{*}{ Model } & \multicolumn{2}{|c|}{ Unstandardized Coefficents } & \multirow{2}{*}{$\begin{array}{l}\text { Standardized } \\
\text { Coefficients } \\
\text { Beta }\end{array}$} & \multirow[t]{2}{*}{$\mathbf{T}$} & \multirow[t]{2}{*}{ Sig } \\
\hline & $\boldsymbol{B}$ & Std.Error & & & \\
\hline Constant & 2,537 & 0,802 & - & 3,16 & 0,000 \\
\hline Persepsi harga & 0,211 & 0,067 & 0,219 & 3,14 & 0,000 \\
\hline Promosi & 0,112 & 0,055 & 0,160 & 2,05 & 0,040 \\
\hline Kualitas layanan & 0,097 & 0,016 & 0,468 & 5,96 & 0,000 \\
\hline
\end{tabular}

Sumber: Output SPSS 22

Hasil pengujian hipotesis pertama menunjukan bahwa terdapat pengaruh positif persepsi harga dengan keputusan pembelian konsumen di Hypermarket di Jakarta. Hasil penelitian ini seusai dengan Penelitian yang dilakukan Oscar dan Keni (2019), Brata, et al. (2017), dan Andreti, et al. (2013) dimana terdapat pengaruh positif persepsi harga dengan keputusan pembelian. Persepsi harga mempunyai peran yang sangat penting dalam keputusan pembelian konsumen. Hasil pengujian hipotesis kedua menunjukan bahwa terdapat bahwa terdapat 
pengaruh positif promosi dengan keputusan pembelian. Hasil penelitian ini seusai dengan Penelitian yang dilakukan Brata et al (2017), Andreti et al (2013), dan Hapzi et al (2018) dimana terdapat pengaruh positif promosi dengan keputusan pembelian di Giant Hypermarket. Promosi menarik tentunya dapat memberikan dorongan bagi konsumen untuk menentukan pilihan nya dalam berbelanja

Hasil pengujian hipotesis ketiga menunjukan bahwa terdapat bahwa terdapat pengaruh positif kualitas layanan dengan keputusan pembelian. Hasil penelitian ini sesuai dengan penelitian yang dilakukan Firdausy dan Idawati (2017), Andreti et al (2013), dan Lahindah et al (2018) dimana terdapat pengaruh positif promosi dengan keputusan pembelian. Kualitas layanan dapat diartikan sebagai upaya pemenuhan kebutuhan dan keinginan konsumen serta ketepatan penyampaiannya dalam mengimbangi harapan konsumen. Kinerja yang diberikan perusahaan harus sesuai dengan harapan konsumen yang terdiri dari layanan yang sama untuk semua konsumen tanpa kesalahan, ketepatan waktu dan sikap yang simpatik juga merupakan suatu hal penting untuk diperhatikan.

Tabel 2

Hasil Uji-F

\begin{tabular}{|l|c|c|c|c|c|}
\hline Model & Sum of Squares & $\boldsymbol{d} \boldsymbol{f}$ & Mean Square & F & Sig \\
\hline Regression & 683,634 & 3 & 227,878 & & \\
\cline { 1 - 4 } Residual & 432,121 & 196 & 2,205 & \multirow{2}{*}{103,360} & 0,000 \\
\cline { 1 - 4 } Total & 1115,755 & 199 & & & \\
\hline
\end{tabular}

Sumber: SPSS 22

Tabel 2 menunjukan bahwa hasil signifikan 0,000 dan nilai berada di bawah nilai 0,05, dapat diambil kesimpulan bahwa $\mathrm{H} 0$ ditolak dan memiliki paling sedikit terdapat satu variabel independen yang mempengaruhi keputusan pembelian.

Tabel 3

Uji R-Square

\begin{tabular}{|l|c|}
\hline Variabel & $\boldsymbol{R}$ Square \\
\hline Persepsi Harga, Promosi dan Kualitas Layanan & 0,613 \\
\hline
\end{tabular}

Sumber: SPSS 22

Berdasarkan hasil analisis diatas, dapat diketahui nilai R-Square adalah $61,3 \%$, artinya perubahan keputusan pembelian dapat dijelaskan oleh perubahan variabel persepsi harga, promosi dan kualitas layanan, sedangkan sisanya 48,7\% dapat dijelaskan oleh variabel-variabel lain yang tidak termasuk dalam penelitian

\section{KESIMPULAN DAN SARAN}

Berdasarkan hasil penelitian mengenai pengaruh persepsi harga, promosi dan kualitas layanan terhadap keputusan pembelia maka dapat disimpulkan sebagai berikut: Terdapat pengaruh positif persepsi harga terhadap keputusan pembelian. Terdapat pengaruh positif promosi terhadap keputusan pembelian. Terdapat pengaruh positif kualitas layanan terhadap keputusan pembelian.

Saran penelitian ini yakni bahwa konsumen Hypermarket melihat sebuah harga merupakan suatu hal yang dipertimbangkan ketika memutuskan berbelanja. Oleh karena itu, dalam menentukan harga tentunya Hypermarket harus lebih berhati-hati dan ditentukan secara matang, Hypermarket harus melihat lagi harga yang di tentukan sehingga persepsi yang dibangun di benak konsumen harga Hypermarket tidak mahal, konsumen saat ini sangat memperhatikan kualitas dibandingkan kuantitas, sesuatu yang cepat dan simpel membuat konsumen betah dan ingin kembali lagi berbelanja di Hypermarket, dengan membuat konsep layanan mengantar barang sampai ke depan kendaraan konsumen ini bisa menjadi opsi Hypermarket dalam meningkatkan kualitas layanan, karena dengan pelayanan ini pelanggan akan merasa terbantu dan diperhatikan. konsumen ingin adanya informasi promosi secara terus menerus, sehingga membuat adanya rasa keingintauan infomasi promosi yang akan dibuat oleh Hypermarket, Hypermarket harus meresponi hal ini. Pihak Hypermarket diharapkan dapat 
mendesain dan memaksimalkan katalog agar bentuk atau tampilan dan isinya dapat diingat untuk kemudian menarik konsumen untuk membeli.

\section{DAFTAR PUSTAKA}

Ali, Hapzi, Evi, N., Nurmahdi, \& Adi. (2018). The influence of Service Quality, Brand Image and Promotion on Purchase Decision at MCU Eka Hospital. Journal of Business and Management Studies, 3(1).

Andreti, J., Zafira, N., Akmal, S., \& Kumar, S. (2013). The analysis of product, price, place, promotion, and service quality on customer's buying decision of convenience store: a survey of young adult in Bekasi, West Java Indonesia. International Journal of Advances in Management and Economics, 72-78.

APRINDO. (2018, 06 22). Pengusaha: Industri Ritel Semester I-2018 Tumbuh 7-7,5\%. Retrieved 2019, from CNBC: https://www.cnbcindonesia.com/news/201806221634064-20125/pengusaha-industri-ritel-semester-i-2018-tumbuh-7-75

Beneke, J., \& Zimmerman, N. (2014). Beyond Private Label Panache; The Effect of Store Image and Perceived Price on Brand Prestige. Journal of Consumer Marketing, 301-311.

Boone, E. L., Kurtz, \& L, D. (2002). Pengantar Bisnis. Jakarta: Erlangga.

Brata, B. H., Husani, S., \& Ali, H. (2017). The influence of quality products, price, promotions, and location to product purchase decision on Nitchi at PT Jaya Swarasa Agung in Central Jakarta. Saudi Journal of Business and Management Studies, 433-445.

Firdausy, C. M., Idawati, \& Rani. (2017). Effects of service quality, price and promotion on customer's purchase decision of Traveloka online airline tickets in Jakarta, Indonesia. International Journal of Management Science and Business Administration, 42-49.

Keni, K., \& Oscar, Y. (2019). Pengaruh brand image, persepsi harga, dan service quality terhadap keputusan pembelian konsumen. Jurnal Muara Ilmu Ekonomi dan Bisnis, 2028.

Kotler, P., \& Keller, K. (2016). Marketing Management (15 ${ }^{\text {th }}$ ed.). Pearson Education Inc.

Lahindah, L., Merisa, \& Siahaan, R. (2018). The influence of product innovation and service quality to buying decision and the impact to repeat buying at Progo Road Bandung. The Asian Journal of Technology Management, 118-124.

Malik, Fozia, Yaqoob, Sara, Aslam, \& Samih, A. (2012). The Impact of price perception, service quality and brand image on customer loyalty (study of hospitality industry in Pakistan). Interdisciplinary Journal of Contemporary Research in Business, 4(5).

Parasuraman, A., Zeithaml, V. A., Leonard, L., \& Berry. (1988). Servqual: a multiple-item scale for measuring consumer perceptions of service quality. Journal of Retailling.

Uma, S., \& Bougie, R. (2016). Research Method for Business (7th ed.). Chichester, West Sussex: Printer Trento Srl. 